\title{
ARGUMENT STRUCTURE IN L2 ACQUISITION: LANGUAGE TRANSFER RE-VISITED IN A SEMANTICS AND SYNTAX PERSPECTIVE
}

\author{
Ricardo Augusto de Souza \\ Universidade Federal de Minas Gerais
}

\begin{abstract}
:
Interlanguage studies tend to be dominated by investigations of strictly morphosyntactic phenomena. Issues of argument structure and argument realization are shown to be a potentially innovative theoretical approach to the study of L2 learners' knowledge of target language grammar, as they are framed as an interface between semantics and syntax. In this article, evidence of language transfer effects in Brazilian L2 learners' representation of transitivity alternations in verbs of manner of movement are presented to support the view that second language research on the acquisition of argument structure realization patterns is a promising line of enquiry.
\end{abstract}

Keywords: Argument structure, language transfer, interlanguage. 


\section{Introduction}

Interlanguage studies constitute an important domain of Second Language Acquisition as a discipline. This claim can be easily testified by a quick look at relevant journals such as Second Language Research and Studies in Second Language Acquisition. When it comes to the acquisition of English as a non-native language, the number of descriptions of interlanguage properties of learners from varied linguistic backgrounds abounds. As highlighted elsewhere (Souza \& Mello, 2007), the growing body of studies on the development of L2 representations of grammar can make a major contribution to the substantiation of theoretically relevant claims about the nature and emergence of non-native language acquisition by documenting robust multilingual evidence. However, there are relatively few contributions derived from empirical work focusing on description and analysis of interlanguages of speakers of Brazilian Portuguese L1. Considering the fact that communicative capacity in foreign languages tends to be highly valued in Brazilian society and that there is a large population of foreign language learners in Brazil, this is a state of affairs seriously in need of being reversed.

In this article, it will be argued that theories of how semantic knowledge and syntactic structures are intertwined when expressions of events and states are configured (i.e. theories of argument realization) may prove an invaluable theoretical approach to the investigation of interlanguage development. To support this argument, evidence that suggests occurrence of language transferone of the cognitive processes that shape interlanguage knowledgewill be presented. Such evidence reveals that a syntactic platform that realizes an argument structure pattern unusual in Brazilian Portuguese is under-represented in the early development of English interlanguage of Brazilian learners. 
In the first section of this article, the notion of argument structure realization within linguistic theory will be reviewed. This review will be followed by a discussion of language transfer as a process in L2 acquisition, and of questions concerning L2 development that brought to the forefront by an argument-structure perspective of predication. In the third and fourth sections, the subjects, the materials, and the method of data gathering and analysis will be reported. The fifth section describes the results obtained, and the sixth discusses them. The article concludes with considerations about how theories of argument structure can motivate second language acquisition studies.

\section{Argument structure: a brief introduction}

Jackendoff $(2002$, p. 137) claims that the problem of argument structure is central to any theory of grammar. An understanding of argument structure is a key to the understanding of predication, hence for an understanding of how events and states are construed through linguistic expression. The most typical kind of lexical item that supports predication is the verb. Thus, an analysis of how argument structure is realized in a given language is ultimately an analysis of how verbs will behave in that language when they express events and states by way of the patterning of clauses.

The linguistic realization of arguments may be regarded as the transition between mental representations of concepts and the manifestations that emerge from them in morphosyntactic structures. Therefore, the semantics of argument realization is of crucial importance, and argument structure should be understood as a component of grammar in which there is an unquestionable interface between semantics and syntax. Therefore, on analyzing argument structure it is useful to draw a theoretical distinction between a semantic argument and a syntactic argument. 
A very useful framework to help readers not fully familiar with theories of argument structure to understand semantic arguments is Harley's (2006) approach of addressing first the notions of nonrelational and relational meanings, or concepts. Whereas the former can de defined as concepts that do not depend on other concepts to be construed, such as the concept of boy and the concept of apple, the latter can only be appropriately construed by simultaneous mental activation of accompanying concepts, or concepts they have a relationship with. One such concept, taken from Jackendoff's (2002) presentation of argument structure, is the concept expressed in English by the verb devour. In order to conceptualize the meaning of this verb, the concepts of a "devourer" and of a "devouree" must also be present as participating concepts. Because of this property, relational concepts such as the meaning encoded by the verb devour are referred to as predicators. When events and states are construed, the concepts that participate in the predication are referred to as the predicator's arguments.

It should be noted, however, that argument structure is more than the specification of participating arguments. The structuring of argument realization in a language such as English also seems to imply specific linking constraints in the choice of syntactic configurations that will satisfy requirements imposed by the argument structure. Considering again a verb such as devour, this can be exemplified in the prompt semantic acceptability of the utterance "the boy devoured the apple". In this utterance, boy and apple are NPs semantically compatible with the concepts of "devourer" and "devouree", a fine compatibility that would not be easily achieved had the utterance been "the apple devoured the boy". In the second utterance there seems to be a violation of a required distribution of arguments that can be formally sketched as X DEVOUR Y, where X must be devourer, 
and $\mathrm{Y}$ devouree. If instead of the highly specific labels "devourer" and "devouree" we choose the more general labels agent and theme, it is not difficult to realize that the argument structure of devour can be stated as X(agent) VERB Y(theme). Furthermore, it is not difficult to realize that this generalization captures an important grammatical similarity between the meaning of devour and that of a vast array of other English verbs, the meanings typically associated with sweep, fix, and carry being but a few examples.

A semantic argument can thus be generally described as a linguistic unit bearing a semantic representation that makes it compatible with the concepts necessary for the construal of relational concepts, then leading to the construal of states and events. That the selection of arguments of a given predicator is to a very large extent determined by the semantics of that predicator is a fact captured by theories of lexical semantics that claim that verbs specify semantic roles that will constrain the possible linguistic units they will cooccur with. Such semantic roles have been labeled thematic roles (theta-roles) (e.g., Jackendoff, 1972) or participant roles (e.g., Van Valin \& La Polla, 1997). Theta-role labels such as "agent", "patient" or "theme", "experience", "instrument", and "beneficiary" illustrate the claim that certain semantic properties are mandatory for an attempted realization of argument structure to be licensed.

As seen above, in the linguistic expression of events and states, semantic arguments must map onto syntactic arguments. Syntactic arguments can be roughly defined as the constituents that will enter in the predication pattern marked as the semantic arguments required by the event or state construal. For example, the sentence "the boy devoured the apple" illustrates a grammatical structure where the semantic argument "agent" maps onto the NP the boy, rendering it the status of a syntactic argument, realized as the grammatical relation 
"subject". By the same token, the semantic argument "theme" maps onto the NP the apple, which is also a syntactic argument, realized as the grammatical relation "object".

A major source of both intralinguistic and cross-linguistic variation in argument realization concerns the different ways through which semantic arguments will map onto syntactic arguments. Within languages, for instance, more than one syntactic platform may represent very similar semantic argument configurations. If one considers the passive voice of the example sentence "the boy devoured the apple", it will be easily noticed that in the resulting configuration the semantic theme maps onto the syntactic subject, and the agent may map onto the complement of a PP (prepositional phrase) headed by the preposition by. Across languages, variation also abounds (Levin \& Rappaport-Hovav, 2005). Variation is probably most notorious with respect to changes in argument structure realization that ensue changes in event construal in relevant ways, a phenomenon referred to as argument structure alternations (Levin, 1993; Levin \& Rappaport-Hovav, 2005). As will be discussed in more detail below, an example of alternation can be found in the agentive verbs of manner of motion such as walk in English and its Portuguese equivalent andar. Whereas in English this verb can easily appear both in one-argument syntactic configurations such as "The boy walked" and in two-argument syntactic configurations like "The boy walked his dog in the park" (with clear further complexity in the event construal), in Portuguese the two-argument syntax would not be likely to find instant acceptance among native speakers.

Because argument structure is clearly a set oflinguistic phenomena that must be conceptualized by the establishment of interfaces between semantic and syntactic representations, theories of argument structure often overlap with theories of the semantic organization of 
language. It is no surprise then that theories of argument structure have motivated theoretical debates around the ultimate roles of semantics in the overall architecture of grammar. In contemporary linguistic theory, accounts and hypotheses about the nature of knowledge of argument structure tend to be schematically grouped into two main theoretical quarters: projectionist and constructionist approaches (Levin, 2004; Levin \& Rappaport-Hovav, 2005).

As Levin (2004) explains, in projectionist approaches differences in argument realization are regarded as deriving almost exclusively from specific encodings of the semantic properties of verbs. Projectionist approaches take a lexicalist position, regarding the specificities of verbs as accountable for the syntactic structures they will be projected onto. In this view, verbs that occur in similar argument structure syntactic patterns are lexical items that share a fundamental semantic representation, or event structure template. Thus, there are verbs that share the event structure [[X] CAUSE [BECOME [Y $<$ STATE $>]]$, such as $d r y$ or empty ${ }^{1}$, these two verbs being members of a verb class that may be defined as "verbs of change of state". The shared event structure of verbs that classify as "change of state" is one of the components of their meaning that is, so to speak, visible to the syntax. This component of meaning prompts the accompanying syntactic constituents (X and $\mathrm{Y}$ in the scheme above) that will participate in the predication. The other components of meaning of the verbs in this class are responsible for the idiosyncratic semantic representations that will distinguish each verb in the class from all the others in the same class, as for instance in the divergent overall meaning of dry and empty.

On the other hand, constructional approaches rely on the concept of "construction", as suggested by the very label "constructional". A construction is defined as a form-meaning pairing. As stated 
by Goldberg (2006), "[a]ll levels of grammatical analysis involve constructions: learned pairings of form with semantic or discourse function, including morphemes or words, idioms, partially lexically fixed and fully general phrasal patterns" (p. 5). In this view, no strict separation between the lexicon and the syntax is put forward. If a given syntactic platform is considered as a construction, it is also assumed to have a semantic base that is not exclusively a byproduct of its component elements. Argument structure patterns are seen as constructions within this approach. Consequently, the verb meanings are not the sole source of argument realization, but rather interact with the meanings of the argument structure syntactic platform. One example is the ditransitive construction (Subj V Obj1 Obj2), the prototypical meaning of which corresponds to "giving". Provided the verb semantics does not contradict the constructional meaning, there could be an exemplar instantiating this construction, such as "Pat sliced Chris a piece of pie" (Goldberg, 2006, p. 7), in which the meaning of slice and the meaning of "giving" engendered by the ditransitive construction overlap. Within this approach, there is no assumption that there is a special lexical entry of slice that triggers the three arguments (agent, receiver, theme). The semantic existence of these arguments stems from the basic meaning of the construction itself.

The lexicalist and the constructional approaches lead to different hypotheses about the nature of knowledge and acquisition of argument structure. In the first approach, knowledge of argument structure is hypothesized as representations of the component of meaning that ranges across verbs within a given class. In the second approach, knowledge of argument structure can be hypothesized as stemming from generalizations based on learned exemplars of more prototypical instances. This theoretical debate may find an invaluable arena for empirical testing and verification in both first and second language acquisition data. 
In the next section the theoretical interest of theories of argument realization to second language acquisition research is addressed, focusing especially on how the concept of L1 influence on L2 learning can be re-visited through them.

\section{L1 influence on L2 learning and the acquisition of argument realization}

Cross-linguistic influence on L2 acquisition has been widely recognized by both practicing language teachers and researchers. Specifically, the role of the mother tongue (L1) in L2 learning has been a major concern in applied linguistic inquiries for some time now. Selinker (1992) offers an historical account of the early systematic analysis of L1 structural manifestations in the foreign language productions of learners. Such early analyses were motivated by the corollaries of behaviorist theory. At that time-when language learning was thought of solely in terms of imitation and habit formationcontrastive structural descriptions of languages were at the core of a research agenda whose main goal was to provide all possible predictions of the difficulties in the path of second language learners, a pursuit that never fully lived up to its promises. Behaviorist-oriented contrastive analysis did nonetheless pave the road to theories of L2 acquisition proposing that this type of human learning is the result of complex psycholinguistic processes stemming from cognitive operations in which L1 knowledge is one factor among several.

It is currently acknowledged that mental representations of the L1 do have a role in L2 learning. However, it is also broadly acknowledged that a full understanding of this role may require theories of language and of language learning that are not limited to surface structural descriptions, as L1 influence on L2 learning may reside beyond what meets the eye. Today, the research agenda 
underpinning the study of L1 influence on L2 learning does not aim at the prediction and elimination of difficulties and errors as its major goal, but rather at deepening our understanding of the very nature of L2 acquisition as a cognitive process, and the psycholinguistic mechanisms operating in it.

The assumption that implicit and even metalinguistic knowledge of the mother tongue (or of another non-native language) is at least one important cognitive factor impinging on the process of L2 learning can be in fact regarded as an almost intuitive notion. After all, unlike infants picking up their first language, L2 learning takes place among individuals who are already speakers of a given language. L2 learners definitely do not start development of communicative capacity through language from scratch. Moreover, it is unquestionable that not only is the L2 learner's departure point different from the L1 acquirer's, but so tends to be the point of their ultimate arrival.

Schachter (1993) points out that knowledge of the L1 may have a deterministic role in configurations of the hypotheses that will be consciously or unconsciously entertained by the L2 learner in relation to the target language input he or she is given. In other words, speakers of a given language come to the task of learning a new language equipped with a cognitive blueprinttheir previous experience as language speakers-that predisposes them to presume the possible shapes a language can take. On the one hand, this cognitive blueprint may prove misleading, making learners resist internalizing structural properties that are crucial to the establishment of a native-like grammar of the L2, in case such properties fail to correspond to the internalized knowledge of language bestowed by the learner's linguistic experience in his or her L1. On the other hand, as discussed in Odlin (1989) and Corder (1993), it can actually be an important learning asset, as 
cross-linguistic shared properties may facilitate internalization of subtle grammatical features.

As argued by Juffs (2000) and Paiva (2009), interlanguage studies that address the issue of L1 influence on interlanguage development have had a salient focus on strictly morphosyntactic phenomena. The focus of research has been on problems such as divergent settings of the pro-drop parameter (Liceras, 1989; Xavier, 2006), pronoun and anaphor binding (Christie \& Lantolf, 1998), and the emergence of projections of functional categories such as AgrP (Agreement Phrase) (Schwartz, 1998; Carneiro, 2008). However, as demonstrated by Juffs (2000) and White (2003), in recent years second language acquisition researchers interested in investigating L1 influences on L2 learning have been drawn to the problem of the development of L2 representations of argument structure, in other words, to matters of semantic representations in L2 grammar.

Research affiliated to the specific interest area of L2 argument structure focuses broadly on how L2 learners come to acquire knowledge of the mappings between semantic representations of predicators and the syntactic configurations such predicators will take part in, along with the accompanying constituents that will be required for full grammaticality/acceptability to be achieved. The problem of L2 development of representations of argument structure can be explicitly posed in the terms of Juffs' (2000, p. 187) question (which focuses on the acquisition of English as a non-native language):

[I]f learners of English as a second language know that both fall and drop mean "to move downwards", do they also know that "the apple fell to the ground", "the apple dropped to the ground", and "Sandy dropped the apple" are possible English sentences, but "`Sandy fell the apple" is not? 
Therefore, from Juff's (2000) argument it can be stated that there are two overarching research questions in the investigation of L2 development of argument realization. One of the questions is whether L2 learners come to mentally represent verbs as belonging to classes marked by association with semantic features that may guide the mapping between the meanings of such verbs and morpho-syntax. Another question is whether learners are capable of forming broad generalizations about verb types and constructional meanings, so that they are able to know that occurrences of certain predicators in certain grammatical constructions are plausible.

An example of this line of investigation is the study reported in Montrul (2001). This is a study that looked at agentive verbs of manner-of-motion (e.g., run, walk, jump, etc) alternating transitivity in English. Verbs of this type in English can take part of intransitive/ transitive alternations, as shown in the examples below (data from MONTRUL, 2001, p):

\section{The soldiers marched.}

2. The captain marched the soldiers to the tents.

As can be seen above, the verb to march can occur in an intransitive construction (sentence 1), where its sole argument is semantically marked as agent. Alternatively, however, it can occur in a transitive construction (as sentence 2) where the basic overall meaning comes to be causation, the causer argument having been mapped to the syntactic subject and the causee argument to the direct object. In other words, the alternating construction seems to be attached to an event conceptualized as composed by two subevents: a causation and the soldiers' march itself. This transitivity alternation can be defined as a caused-motion alternation. 
As pointed out by Montrul (2001), quoting Ritter \& Rosen $(1998)^{2}$, there are clear semantic constraints in operation with respect to such alternation. Namely, a prepositional phrase ("to the tents" in sentence 2) or other sign of an end point seems crucial for acceptability, as for the alternation to be licensed there must be a reading that evokes telicity of the depicted event. Had the event been construed as atelic (a possible reading for sentence 1), the alternation would not have been licensed, as illustrated in sentence 3 below:

\section{3. ${ }^{*}$ The captain marched the soldiers.}

In her study, Montrul examined the influences of L1 Spanish, L1 English and L1 Turkish in L2 English and L2 Spanish interlanguages. Specifically, the researcher sought to investigate if L1-induced overgeneralizations or undergeneralizations would take place. English and Spanish evince cross-linguistic divergences in the behavior of agentive verbs of motion. Notably, English allows transitivity alternations of the type described above involving manner-ofmotion verbs, whereas Spanish and Turkish do not. As the grammar of English has a broader scope of possible constructions compared to the grammar of either Spanish or Turkish regarding verbs of this type, the cognitive task facing a learner of L2 Spanish whose L1 is English, for instance, would be to restrict the scope of his or her interlanguage representation. Contrastively, the cognitive task facing the English L2 learner whose mother tongue is Spanish is to achieve knowledge of the semantic features that will allow generalization of a construction new to his or her previous linguistic experience.

Taking Montrul (2001) as a point of departure, the author of the present paper carried out an empirical study that aimed to gather evidence of L1 influence in L2 acquisition of argument realization from Brazilian Portuguese-speaking learners of English as an L2. 
Assuming that Brazilian Portuguese behaves in a manner similar to the description of Spanish reported in Montrul's study with respect to the caused-motion alternation, the present study aimed at answering two major research questions. The first question was whether significant distinctions between Brazilian Portuguese speakers' and English speakers' representations of the caused-motion construction do exist. In the case of an affirmative answer to the first question, the second question would be whether evidence of language transfer that can be associated with this distinction would be found.

We now proceed to the details of our study.

\section{Subjects of the study}

The present article reports on a subcomponent of a broader research project that encompasses empirical studies planned to fit a quasi-experimental research design, with both statistical analyses of quantitative (quantified objective test responses) and qualitative analyses of elicited linguistic performance data. The subcomponent here reported relies on analyses of the quantitative data only.

A total pool of 59 subjects took part in the study reported here. Out of these, 39 were freshmen in the English Language and Literatures major of the Federal University of Minas Gerais, a large Brazilian public university, and had at least an intermediate level of communicative ability in English (a requirement for entry in their college major). They were further divided into two groups based on the results of a test of lexical competence, described in detail below. These were the experimental groups of the study. The 20 remaining subjects were all college students, but not English majors: 10 were native speakers of Brazilian Portuguese who did not speak English (self-report), and 10 were native speakers of English (a mixed group of Americans, Australians, and New Zealanders) who had recently arrived in Brazil to take a one-month intensive course in Portuguese 
as a foreign language. These two groups of ten subjects each formed the control groups of the study.

The pool of subjects of the study formed a roughly balanced mix of females and males, and they were all in their late teens and beyond. As age and gender were not variables in the present study, specific data or observations concerning such information were neither collected nor registered.

All subjects that participated in this study signed consent letters after being informed in lay terms that the focus of the study was the understanding of L2 speakers' knowledge of specific features of their second language grammar, that the data they provided would be anonymously codified and quantified, and that their participation of the study was fully optional and non-interfering with their academic progress at the university.

\section{Materials and methods}

The 39 learners of English who formed the experimental groups in the study were submitted to a sequence of two tests, administered over a couple of 20-40 minute testing sessions.

The first test aimed at grouping subjects with respect to their proficiency level. A vocabulary test (Nation, 1990) was chosen for this purpose. The reason for the choice of a lexical competence measure was motivated primarily by theoretical concerns, since, as discussed earlier, argument structure realizations are understood as matters of lexicalization strategies. Thus, identification of interlingual approximations with native speakers' licensed argument structure patterns in association with L2 vocabulary development is a plausible interlanguage strategy.

Nation's (1990) test is a five-part battery. Each part displays six sets of six lexical items paired-up with lists of three words that are 
synonymous to the lexical items in the set. The test-taker's task is to match three of each set's lexical items with their potential synonyms. The test places subjects in a four-band lexical competence scale. The most interesting feature of this vocabulary test for the purposes of this study is the fact that it is fully based on identification of word correspondences. Therefore, it is supposedly a pure measure of vocabulary (excluding knowledge of particular syntactic structures). This feature made Nation's test neutral with respect to the theoretical views of argument structure representations discussed above, as it could accommodate both the view of a separate-from-syntax lexicon and the view of mental storage of constructions (assuming no sharp distinction between the lexicon and the syntax) as the key to knowledge of argument structure realization patterns.

All 39 learners in the study were placed between bands 2 and 3 of Nation's vocabulary test, thus producing two groups, the first with 19 subjects placed in band 2 of the test and the second with 20 subjects placed in band 3. For the sake of the present article, the groups obtained following the scoring of the vocabulary tests were labeled the lower lexical proficiency group (LP), and (2) the higher lexical proficiency group (HP).

Subsequent to the administration of the vocabulary tests, the subjects of the experimental groups were submitted to an acceptability judgment test. In this test, subjects were presented five sets of three sentences containing roughly equivalent wordings. The sentences in each set differed in that one of them instantiated verbs of manner of motion in the causative syntactic configuration, one of them instantiated a periphrastic construction in which the [X CAUSE Y] semantic template was born by the verb make or take, and one of them was a distractor involving an adjunct prepositional phrase headed by with. It should be observed that none of the three sentences in the five 
sets was actually ungrammatical. A few of them might be perceived as infelicitous from a pragmatic viewpoint, though.

The complete corpus of fifteen sentences for the acceptability judgement test is displayed below:

\begin{tabular}{ll}
\hline Verb & Sentence \\
\hline Run & The psychologists made the rat run through the maze. \\
Run & The psychologists ran with the rat through the maze. \\
Run & The psychologists ran the rat through the maze. \\
Walk & Dan and Rose love to walk their dog in the park. \\
Walk & Dan and Rose love to walk with their dog in the park. \\
Walk & Dan and Rose love to take their dog to walk in the park. \\
March & The captain made his troop march along Main Avenue. \\
March & The captain marched with his troop along Main Avenue. \\
March & The captain marched his troop along Main Avenue. \\
Jump & Tom could make his horse jump over the first fence. \\
Jump & Tom could jump his horse over the first fence. \\
Jump & Tom could jump the first fence with his horse. \\
Fly & We liked to make kites fly in the afternoon. \\
Fly & We liked to fly with kites in the afternoon. \\
Fly & We liked to fly kites in the afternoon. \\
\hline
\end{tabular}

Figure 1: The Acceptability Judgement Test Corpus.

In the testing sessions, subjects were exposed to the corpus sentences through a slide show in which each of the sentences was displayed for analysis for 60 seconds. The subjects were asked to register their judgement of the perceived naturalness of each 
sentence by marking a five-point Likert-scale ranging from "totally unacceptable" to "perfectly natural" on hand-outs in their possession at the time of the slide show presentation. The following figures (Fig. 2 and 3) exemplify one of the slides and the graphic display of the Likert-scale in the subjects' hand-outs.

\section{Situation D}

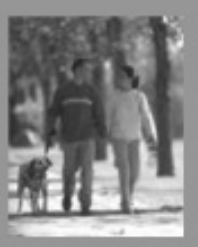

1. Dan and Rose love to walk their dog in the park.

2. Dan and Rose love to walk with their dog in the park.

3. Dan and Rose love to take their dog to walk in the park.

Figure 2: Slide show sample in the Acceptability Judgement Test.

Judge the sentences shown for each situation according to the following scale:

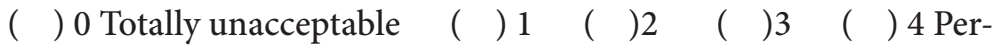
fectly natural

\begin{tabular}{|c|c|c|c|c|}
\hline \multicolumn{5}{|c|}{ Situation D } \\
\hline $\begin{array}{l}\text { Sentence 1: } \\
\text { ( ) } 0\end{array}$ & ( ) 1 & ( ) 2 & ( ) 3 & ( ) 4 \\
\hline
\end{tabular}




\begin{tabular}{|l|l|l|l|l|}
\hline $\begin{array}{l}\text { Sentence 2 } \\
(\quad) 0\end{array}$ & $(\quad) 1$ & $(\quad) 2$ & $(\quad) 3$ & $(\quad) 4$ \\
\hline $\begin{array}{l}\text { Sentence 3 } \\
(\quad) 0\end{array}$ & $(\quad) 1$ & $(\quad) 2$ & $(\quad) 3$ & $(\quad) 4$ \\
\hline
\end{tabular}

Figure 3: Sample fragment of subejcts' hand-out in the Acceptability Judgement Test.

The same acceptability judgement test administered to the experimental group subjects was also administered to subjects in the English-speaking control group. A translated version of the acceptability judgement test was administered to the Portuguesespeaking control subjects. The translations were nearly literal, with maintenance of both the potentially unlicensed (with respect to Portuguese) transitivity alternation with the corresponding verbs of manner of motion, four instances of periphrastic forms containing a finite instance of the Portuguese equivalent to make (fazer), and one instance of a Portuguese equivalent of take the dog to walk (levar o cachorro para andar).

In order to verify the hypotheses that speakers of Brazilian Portuguese would reject the syntactic platform of the caused-motion alternation, and that language transfer effects would occur among L2 English learners of Brazilian Portuguese L1 background because of the contrast between English and Brazilian Portuguese, the responses of the two experimental groups and the two control groups were statistically compared and contrasted through administration of the Kruskal-Wallis test, which discriminates between groupings of nonparametric data. Kruskal-Wallis was favored over ANOVA because of the relatively limited number of subjects in all groups. Statistically significant differences between groups are considered to exist when the p-values obtained in the Kruskal-Wallis test are lower than 0.05. 
The results of the statistical data analysis are presented in the next section.

\section{Results}

As stated above, the two experimental groups of Brazilian Portuguese speaking learners of English were obtained through administration of Nation's (1990) vocabulary test. These groups are identified here as the LP group (lower lexical proficiency group, with 19 subjects), and the HP group (higher lexical proficiency group, with 20 subjects). The control groups, each with 10 subjects, are identified here as the BP group (speakers of Brazilian Portuguese), and the EN group (speakers of English).

The Likert-scale acceptability judgement distributions for the five sets of three sentences of the four groups are graphically presented in the figures below. Each figure gathers the graphics for the three sentences in each of the five manner-of-motion verbs. Readers are reminded that the BP group was exposed to near-literal translations of the sentences in the English corpus. In order to facilitate reference to the results discussed in each sentence set, a reproduction of sentences judged is given prior to the corresponding figure.

5.1- Judgement of constructions with verb "run".

Sentence 1 The psychologists made the rat run through the maze.

Sentence 2 The psychologists ran with the rat through the maze.

Sentence 3 The psychologists ran the rat through the maze. 
Analysis of Constructions with Run - Correr

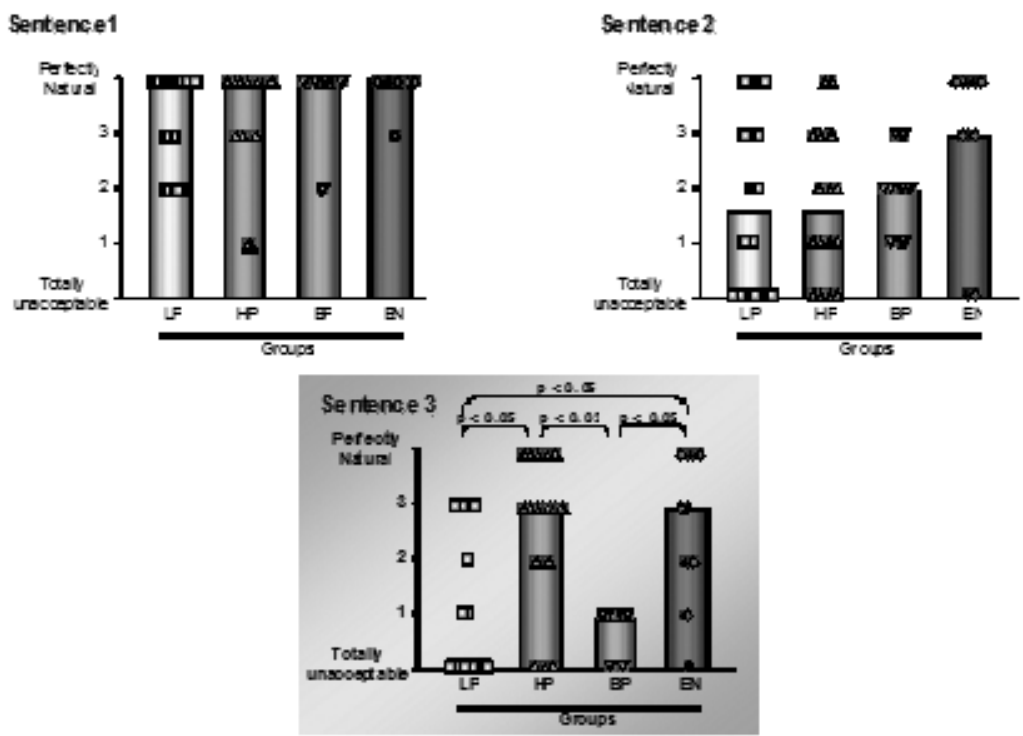

Figure 4: Analysis of Constructions with Run/Correr.

As can be seen in Figure 4, all four groups judged sentence one highly acceptable. This sentence contains a periphrastic causative construction, with the verb make. Sentence two, a distractor containing a prepositional phrase headed by with, was interestingly more severely rejected by the speakers of Portuguese (both in the experimental and in the control group) than by the English speaking subjects. Nevertheless, the groups were not statistically different with respect to their response to this sentence.

Sentence three is the sample of the target structure, and it is in the judgements for this sentence that statistically significant differences between groups are found. It should be observed first that the BP group is different from the EN group, indicating that 
whereas the English speaking subjects tend to find the causedmotion transitivity alternation reasonably acceptable, the equivalent Portuguese structure is rejected by the Brazilian Portuguese subjects. It is noteworthy that rejection of the sentence pattern is even more evident when the lower proficiency learners were exposed to it in English. This group is different in their judgements from both the $\mathrm{EN}$ and the HP groups, as can be seen in the $\mathrm{p}<0.05$ values indicated in the figure. By contrast, the HP group tends to judge this sentence pattern in a way fairly similar to the EN group, being at the same time statistically different from both the BP and the LP groups.

5.2- Judgement of constructions with verb "walk".

\begin{tabular}{ll}
\hline Sentence 1 & Dan and Rose love to walk their dog in the park. \\
Sentence 2 & Dan and Rose love to walk with their dog in the park. \\
Sentence 3 & $\begin{array}{l}\text { Dan and Rose love to take their dog to walk in the } \\
\text { park. }\end{array}$ \\
\hline
\end{tabular}


Analysis of Construdions with Walk - Andar
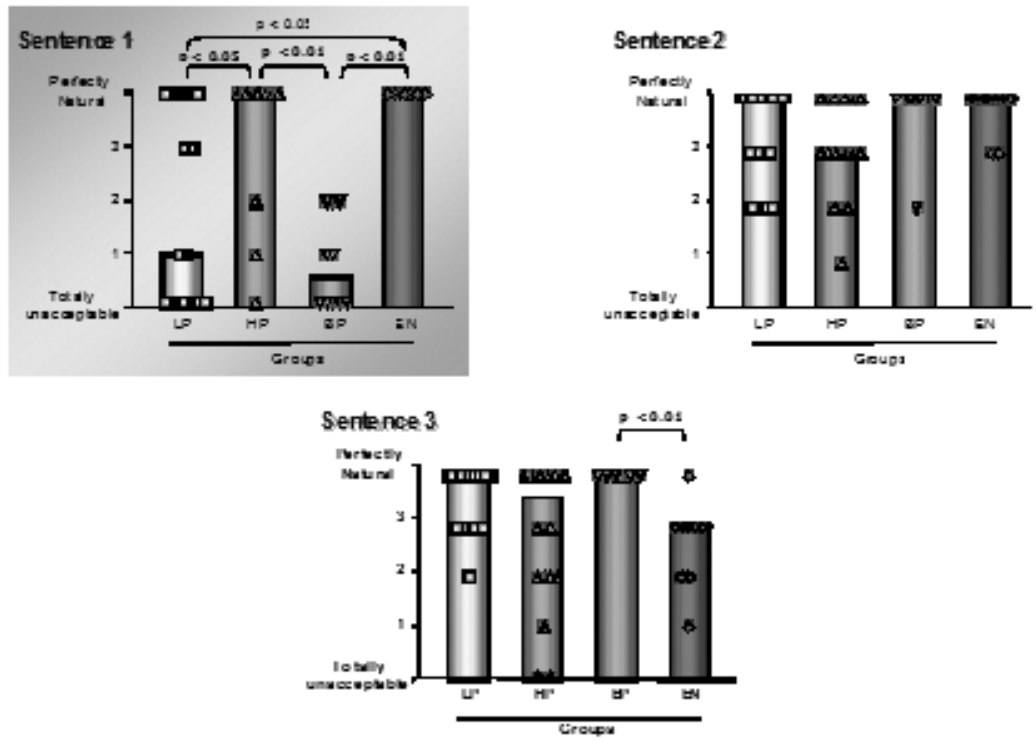

Figure 5: Analysis of constructions with walk/andar.

Sentence one exemplifies the caused-motion alternation. The statistical analysis reveals that the tendency in acceptability perceptions of the BP group and the LP group is very similar, as both tend to reject walk/andar as a causative transitive verb. This makes both the LP and the BP group significantly different from HP and EN, as the latter groups are similar with respect to their high mean rate of acceptability of the target syntactic pattern. It is noteworthy that the p-values in the comparison of both HP and EN with BP are actually $\mathrm{p}<0.01$, thus indicating that their acceptance of the construction Dan and Rose love to walk their dog in the park is remarkably distant from the acceptance of the Portuguese counterpart of the same sentence by the Brazilian Portuguese speaking subjects. 
The second sentence, a distractor with a PP headed by with, was highly accepted by all three groups, with a lower mean acceptance rate among HP subjects that did not lead to discrimination between them and the other groups. The high acceptance of this sentence may be explained by the fact that, unlike other distractor sentences with the same PP in the experimental corpus, the sentence with the verb walk and its Brazilian Portuguese counterpart are both semantically and pragmatically acceptable. Sentence three, the only one in the corpus that does not employ the verb make (take is used instead), is on the average well accepted by all groups, EN subjects having the lowest mean rate. The contrast between the English speakers' mean acceptance rate for this sentence and the $100 \%$ top acceptability of the BP subjects to the Portuguese counterpart "Subject + levar o cachorro para andar" can be considered an indicator of the idiomaticity of the Portuguese language construction. The unanimous top acceptance of the sentence by the BP subjects is most probably the statistical cause of the sharp difference between them and the EN subjects $(p<0.01)$, even though the mean rate given by the speakers of English as a group is not actually low. The judgement of the Portuguese sentence as perfectly natural by $100 \%$ of the BP subjects makes it indeed an extremely suitable counterpart to the English construction "Subject + walk the dog"-sentence 1 -which was judged perfectly natural by $100 \%$ of the native speakers of English.

\section{3- Judgement of constructions with verb "march".}
Sentence 1
The captain made his troop march along Main Av- enue.
Sentence 2 The captain marched with his troop along Main Avenue.
Sentence 3 The captain marched his troop along Main Avenue. 


\section{Analysis of Construdions with March - Marchar}

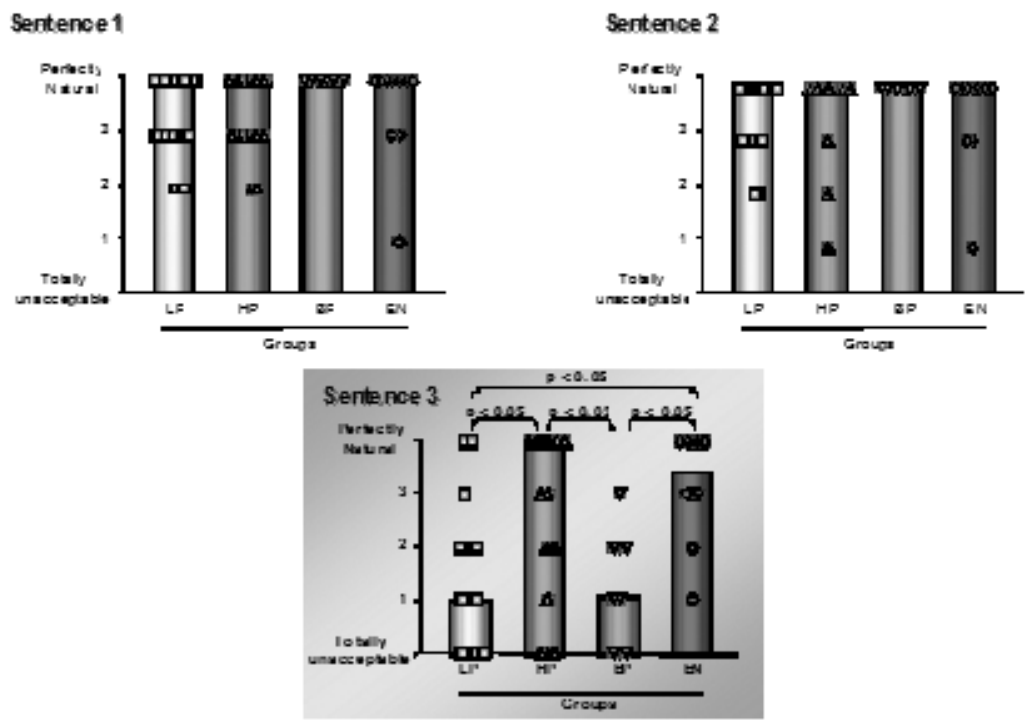

Figure 6: Analysis of constructions with march/marchar.

The acceptability rates of all four groups for the first and the second sentences indicate that the English and the Portuguese sentences with both a make causative and with a with-headed PP are regarded well-formed.

On the other hand, the sentences instantiating the causedmotion transitivity alternation of march/marchar make BP and LP subjects contrast with HP and EN, with only the latter groups judging the syntactic pattern acceptable. The p-values $(\mathrm{p}<0.05)$ discriminating LP from both HP and EN, and HP and EN from BP, together with the low mean acceptability rate obtained from both LP and BP (an average of 1 point in the five point scale) reveal that the higher proficiency and the English L1 speaking groups' tendencies 
depart from the Brazilian Portuguese speakers', whereas the lower proficiency group's does not.

\section{4- Judgement of constructions with verb "jump".}

\begin{tabular}{ll}
\hline Sentence 1 & $\begin{array}{l}\text { Tom could make his horse jump over the first } \\
\text { fence. }\end{array}$ \\
Sentence 2 & Tom could jump his horse over the first fence. \\
Sentence 3 & Tom could jump the first fence with his horse. \\
\hline
\end{tabular}

\section{Analysis of Construdions with Jump-Satar}
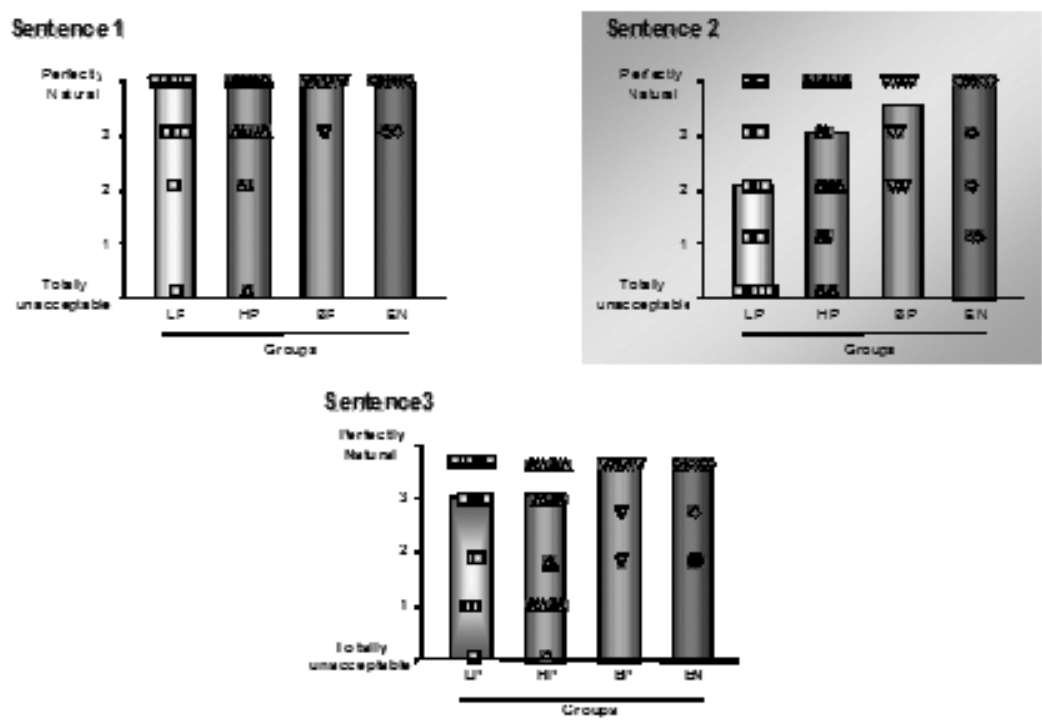

Figure 7: Analysis of constructions with jump/saltar.

The results of the acceptability judgement of sentence two of the set of sentences with jump/saltar are somewhat surprising. The comparison between how the Portuguese sentence is judged by BP 
subjects and how its English counterpart is judged by EN suggests that the two groups did not actually differ, indicating that a caused-motion syntactic platform with the specific verb of the Portuguese language is perceived as licensed by the native Brazilian subjects. Even though no statistically significant difference was identified among the four groups with respect to this sentence, the lack of contrast between the BP and $\mathrm{EN}$ groups is particularly interesting with respect to the reasonable cluster of "totally unacceptable" ratings among subjects in the LP group. In other words, unlike the other verbs in the experimental corpus of the present study, in the caused-motion construction with transitive jump, the lower proficiency group departed from the judgements that other speakers of Brazilian Portuguese gave to a syntactically identical Portuguese sentence. Observation of the mean ratings achieved by each group seems to suggest that actually both groups of learners of English behaved differently from the Brazilian Portuguese controls in face of the English language input, tending to reject it more.

Regarding the sentences with make and the with-headed PP, the judgements supplied by all groups of subjects in the present study indicate that they are well-formed, generally acceptable constructions.

\section{5- Judgement of constructions with verb "fly".}

Sentence $1 \quad$ We liked to make kites fly in the afternoon.

Sentence 2 We liked to fly with kites in the afternoon.

Sentence 3 We liked to fly kites in the afternoon. 


\section{Analysis of Construdi ons with Fly - Voar}
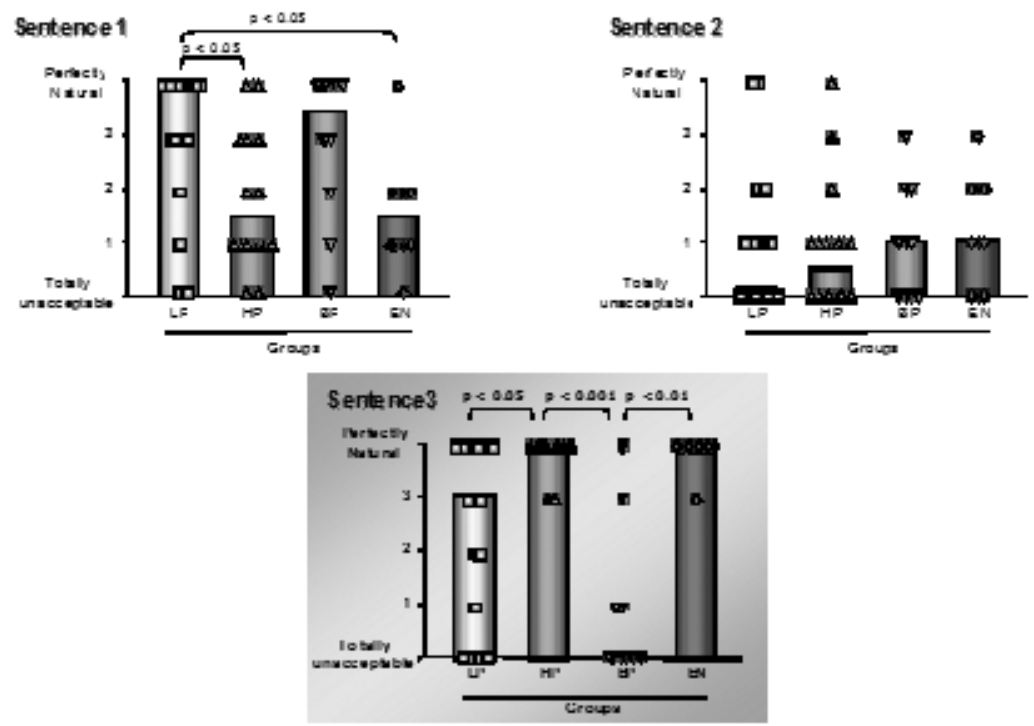

Figure 8: Analysis of constructions with fly/voar.

The acceptability rates given by the four groups of subjects to the periphrastic make causative with the verb fly-sentence one in this set-is the only instance of such periphrastic construction in the experimental corpus where significant differences were identified. In this sentence, the HP and the EN subjects were comparable in their refusal of this construction as acceptable, whereas the LP and BP subjects demonstrated parallel behavior. P-values indicating statistically significant differences $(\mathrm{p}<0.05)$ discriminate between LP subjects and both HP and EN, as can be seen above. Sentence two, the distractor instantiating a PP headed by with was generally rejected by all four groups, probably a reflection of the obvious 
infelicity of the utterance "We liked to fly with kites in the afternoon" from a pragmatic point of view.

The transitive use of fly in the caused-motion construction is instantiated in the third sentence of this set. Its Portuguese language counterpart is utterly rejected by $60 \%$ of the Brazilian Portuguese natives, who rated it "totally unacceptable". However, the English sentence is judged "perfectly natural" by $90 \%$ of the native speakers of English in the study, suggesting that it is probably highly idiomatic and frequent in English. An identical tendency in judgement was found among the HP learners, $90 \%$ of whom also rated the sentence "perfectly natural", and both HP and EN are strikingly different from BP in a statistically significant manner $(\mathrm{p}<0.001$ and $\mathrm{p}<0.01$ respectively). Although the p-value obtained in the Kruskal-Wallis test discriminates between the LP subjects and the HP subjects, the cluster of subjects in the LP rating the English sentence "perfectly natural" seems to indicate that even among subjects in this group a reasonable departure from the what is acceptable in Portuguese is also taking place.

We now proceed to a discussion of the results presented here.

\section{Discussion}

Significant differences were obtained between native speakers of Portuguese and native speakers of English when these two groups of subjects were presented with the syntactic platform of four of the five verbs in the experimental corpus instantiating the causedmotion alternation. This finding is strong evidence that the causedmotion alternation is indeed a type of argument structure realization pattern that is not normally represented in the grammar of speakers of Portuguese. It is the case that interlanguage representations of this construction will need to be learned as a new syntactic configuration 
by the acquirer of English as a foreign or second language whose native language is Brazilian Portuguese, as knowledge of their mother tongue will not provide them with structural hints that a sentence of this kind is possible in their target language.

A surprising exception is the high acceptability of the causedmotion alternation with verb jump/saltar by both native speakers of Brazilian Portuguese and native speakers of English. Further explorations need to be made in order to clarify why this result was obtained. One hypothesis is that the image of a jockey and horse jumping over a fence may prompt readers of the accompanying sentences (Tom could make the horse jump over the first fence, Tom could jump over the first fence with his horse, and Tom could jump his horse over the first fence) to perceive them as equally linked to the scene from a semantic-pragmatic point of view, in both Portuguese and English. If this is the case, then a less likely choice of agent NP for jump, such as the already used rat could lead to different results. This is of course a matter to be sorted out in replications of this study.

The results presented above indicate that the lower proficiency EFL learners seem to behave in alignment with native speakers of Portuguese when they process the caused-motion alternation with the verbs run, walk, march, and fly. The fact that their behavior with respect to these constructions is in sharp contrast with the behaviors evidenced by higher proficiency learners and native speakers of English is a strong hint at the possibility that language transfer impinges on their representation of argument realization in English.

An interesting detail concerning interlanguage as a knowledge system relatively independent from both the learner's L1 and the L2 (a hypothesis put forward by Selinker) can be found in the responses given to the sentences with jump. As can be verified in the corresponding figure, whereas native speakers of Portuguese tended 
to fully accept the alternating-like Portuguese sentence with saltar, it is visible that in fact the lower level learners were the most severe subjects in their rejection of the English alternating sentence. This may indicate that even though they could have found the sentence plausible had it been in Portuguese, they may have found it too divergent from their current interlanguage grammar representation.

On the other hand, the fact that the higher proficiency learners behave similarly to native speakers of English in their acceptance of the caused-motion alternation is very clear evidence that there is a stage of interlanguage development when this type of construction is represented. We can hypothesize that even though the sort of syntactic pattern exploited in this study is under-represented early in the interlanguage of Brazilian Portuguese-speaking learners of English, there will be a stage when this state of knowledge will be altered either as a consequence of exposure to L2 input or as a consequence of interventions.

The findings for the higher level learners in this study do not, however, justify a definite claim on the learnability of second language argument structure. It may be the case that the non-native subjects have been previously exposed to caused-motion constructions with the particular verbs they judged acceptable in the study described above. In order to make more robust claims about native-like learnability, learners would have to demonstrate the capacity to employ a whole class of verbs whose semantic properties match those of the verbs of this study in the construction, even novel verbs. This is clearly beyond the scope of the present study. It is nevertheless an issue that motivates further explorations.

Finally, it would also be worth exploring whether or not the different linguistic background/ability levels groups in this study interpret the sentences in similar ways. The very notion of 
construction as a form-meaning pair may make us wonder whether under-representation of a syntactic pattern as the proper lexicalization of a conceptualized event equates with under-representation of the associated semantics. Further exploration involving verbal protocols or other forms of determining how the sentences are actually read can certainly shed light on the nature of L2 learners' transitional knowledge of language forms.

\section{Conclusion}

This article discussed the adequacy of theories of argument realization in studies of interlanguage properties. The position was defended that such theories provide L 2 researchers with a potentially profitable approach to investigate the development of L2 learners' representations of grammar because they offer insights about the mappings of conceptualizations and their linguistic expression. The data presented and discussed were considered evidence that the contrasts between Brazilian Portuguese and English with respect to the availability of transitivity alternations of verbs of manner of motion affect English L2 learners' early knowledge of these structural possibilities of their target language, as they are not represented in their interlanguage grammars. The data also indicate that causedmotion alternations do appear in learners' repertoire at later stages of interlanguage development. As discussed above, questions concerning the extent to which the later-stage representations are productive (ultimately, a question concerning item versus system learning), and also the extent to which meaning-form associations are equally represented between natives and non-natives were not addressed in the present study. Neither were issues concerning the liability of such representations to alter in response to specific instructional measures. These are matters that could be interestingly investigated within the framework of enquiry explored here. 


\section{Notes}

1. A sentence such as "Mary emptied the bin", for example, where "Mary" and "the bin" are respectively the arguments valuing variables (X) and $(\mathrm{Y})$ could be analyzed as ultimately derived from the event structure [[Mary] [CAUSE [BECOME [the bin <empty>]]].

2. RITTER, E. \& ROSEN, S. “Delimiting Events in Syntax”. In M. Butt \& W. Geuder (Eds.) The Projection of Arguments: Lexical and compositional factors. Stanford, CA: CSLI Publications, 1998.

\section{References}

Carneiro, M. M. (2008). Morfologia de flexão no inglês como L2. Unpublished Master's Thesis. Belo Horizonte, Brazil: Faculdade de Letras da Univesidade Federal de Minas Gerais.

Christie, K. \& Lantolf, J. (1998). Bind me up bind me down: Reflexives in L2. In Flynn, S.; Martohardjono, G.; O’Neil, W. (Eds). The generative study of second language acquisition (pp. 239-260). Mahwah, NJ: Lawrence Erlbaum Associates.

Corder, S. P. (1993). A role for the mother tongue. In Gass, S. \& Selinker, L. (Eds). Language transfer in language learning (pp. 18-31). Philadelphia, PA: John Benjamins.

Goldgerg, A. (2006). Constructions at work. New York, NY: Oxford University Press.

Harley, H. (2006). English words: A linguistic introduction. Malden, MA: Blackwell Publishers.

Jackendoff, R. (1972) Semantic interpretation in generative grammar. Cambridge, MA: The MIT Press.

Jackendoff, R. (2002). Foundations of language-Brain, meaning, grammar, evolution. New York, NY: Oxford University Press.

Juffs, A. (2000). An overview of the second language acquisition of links between verb semantics and morpho-syntax. In Archibald, J. (Ed). Second Language Acquisition and Linguistic Theory (pp. 197-227). Malden, MA: Blackwell Publishing. 
Levin, B. (1993). English verb classes and alternations: A preliminary investigation. Chicago, IL: University of Chicago Press.

Levin, B. (2004) Verbs and constructions: Where next? Retrieved February 2009 from http://www.stanford.edu/ bclevin/pubs.html.

Levin, B. \& Rappaport-Hovav, M. (2005). Argument realization. New York, NY: Cambridge University Press.

Liceras, J. M. (1989). On some properties of the 'pro-drop'parameter: looking for missing subjects in non-native Spanish. In Gass, S. \& Schachter, J. (Eds). Linguistic perspectives on second language acquisition (pp. 109-133). New York, NY: Cambridge University Press.

Montrul, S. (2001). Agentive verbs of manner and motion in Spanish and English as second languages. Studies in Second Language Acquisition, 23, 171-206.

Nation, I.S.P. (1990). Teaching and learning vocabulary. Boston, MA: Heinle \& Heinle.

Odlin, T. (1989). Language transfer. New York, NY: Cambridge University Press.

Paiva, V. L. M. O. (2009). Second language acquisition: from main theories to complexity. Retrieved February 2009 from http://www.veramenezes.com/slatheory.pdf .

Schachter, J. A (1993). A new account of language transfer. In Gass, S. \& Selinker, L. (Eds.) Language transfer in language learning (pp. 98-111). Philadelphia, PA: John Benjamins.

Selinker, L. (1972). Interlanguage. IRAL, 10, 209-231.

Selinker, L. (1992). Rediscovering interlanguage. New York, NY: Longman Group Ltd.

Schwartz, B. (1998). On two hypotheses of 'transfer' in L2A: Minimal trees and absolute L1 influence. In Flynn, S.; Martohardjono, G.; O’Neil, W. (Eds). The generative study of second language acquisition (pp. 35-59). Mahwah, NJ: Lawrence Erlbaum Associates.

Souza, R. A. \& Mello, H. R. (2007). Realização argumental na língua do aprendiz de línguas estrangeiras - Possibilidades de exploração da in- 
terface entre semântica e sintaxe. Revista Virtual de Estudos da Linguagem, 8. Retrieved March 2009 from http://www.revel.inf.br.

Van Valin, R. \& LaPolla, R. (1997). Syntax: Structure, meaning and function. New York, NY: Cambridge University Press.

White, L. (2003). Second language acquisition and Universal Grammar. New York, NY: Cambridge University Press.

Xavier, G. R. (2006). Português brasileiro como segunda língua: Um estudo sobre o sujeito nulo. Unpublished Ph.D Dissertation. Campinas, Brazil: Universidade de Campinas. 
